\title{
THE EFFECT OF ORAL CLONIDINE AT DIFFERENT DOSES ON POST-OPERATIVE ANALGESIC AND HEMODYNAMIC STATUS IN UPPER ABDOMINAL SURGERY
}

\author{
MONDOL MSH ${ }^{1}$, DAS RS $^{2}$, ALI D $^{3}$, SHATHI IJ ${ }^{4}$, MIAH MAK $^{5}$, RAHMAN CMM $^{6}$, AZAD KAK $^{7}$
}

\begin{abstract}
Background: Upper abdominal surgery (like- hepatobiliary surgery, gastrectomy, esophagectomy, hepatictomy, and whipples operations that involve large surgical incisions) lead to severe postoperative pain that lead to higher doses of opoids use in post-operative period as a result incidence of unwanted side effect and respiratory complication increase hospital stay and morbidity. To reduce the use of opioids clonidine can be used as a multimodal analgesic approach. It is reported that clonidine $150 \mathrm{mcg}$ intravenous (I/V) produce a similar analgesic effect to morphine $5 \mathrm{mg}$ in patient after orthopedic surgery. Because of its dose, route, and surgical variation it is very much important to specify the dose for upper abdominal surgery.
\end{abstract}

Material and methods: After considering the inclusion and exclusion criteria the patients were randomized to receive Group: A ( $2 \mathrm{mcg} / \mathrm{kg}$ oral clonidine) and Group: B ( $4 \mathrm{mcg} / \mathrm{kg}$ oral clonidine), one hour (60minutes) before surgery as an oral premedication. All groups were compared for preoperative analgesic, sedation and anxiety level along with changes of heart rate and mean arterial pressure prior to premedication and post-operative periods as follows VAS (visual analogue score) pain scores.

Result: The post-operative pain measured on VAS showed Group A expressed highest VAS at $6^{\text {th }}$ post-operative hour Group $-B$ showed highest VAS at $14^{\text {th }}$ post-operative hour. So it is very clear to us that pethedine requirement of Group B $(4 \mathrm{mcg} / \mathrm{kg}$ oral clonidine) is less than Group A (2mcg/ $\mathrm{kg}$ oral clonidine).

The oral premedication with clonidine at 2 microgram per $\mathrm{kg}$ or 4 microgram per $\mathrm{kg}$ for postoperative analgesia and hemodynamic stability of elective upper abdominal surgery patients.

Conclusion: As a part of multimodal analgesic approach, $4 \mathrm{mcg} / \mathrm{kg}$ oral clonidine premedication is effective to perioperative pain control and keep stable the haemodynamic in upper abdominal surgery

Key words: Clonidine, Post-Operative Analgesic, Abdominal Surgery.

J Dhaka Med Coll. 2019; 28(2) : 131-135

\section{Introduction :}

Usually Opiods are used as good analgesic, but have some adverse effect and addiction effect; anaesthesiologists want to reduce its requirements. In upper abdominal surgery adequate analgesia, stable haemodynamic, early bowel movement, free from nausea and vomiting is wanted, as a part of multimodal analgesic approach, premedication by clonidine is very important for it analgesic, anxiolytic and

1. Dr. Mohammmad Shaddam Hoshain Mondol, Anesthesiologist. dept. of anesthesia, analgesia, palliative and intensive Care medicine $\mathrm{DMCH}$

2. Dr. Rajat Shuvra Das, Specialist, department of anaesthesia, BRB Hospital ltd. Panthopath, Dhaka.

3. Dr. Md. Arman Ali, Anesthesiologist. Dept. of anesthesia, analgesia, palliative and intensive care medicine, $\mathrm{DMCH}$

4. Dr. Ishrat Jhahan Shathi, Assistant Prof. conservative dentistry and endodontic, SSMC.

5. Dr. Mohammad Abdul Karim Miah, Assistant prof, DMCH

6. Dr. Chowdhury Md. Mushfiqur Rahman, Assistant Professor, Department of Ear, Nose and Throat, Dhaka Medical College.

7. Prof. Khan Abul Kalam Azad, Professor of Medicne \& Principal, Dhaka Medical College, Dhaka

Correspondence: Dr. Mohammmad Shaddam Hoshain Mondol, Anesthesiologist. dept. of Anesthesia, Analgesia, palliative and intensive care medicine DMCH, Mobile: 01780369159, Email- shaddamhmbd@gmail.com 
sedative properties. Alpha two (á-2) adrenoreceptor agonist, Clonidine exerts central sympatholytic effect for 8 to 10 hours as its half life is $9-12 \mathrm{~h}$. So that premedication with oral clonidine causes reduction of anxiety, reduction of perioperative analgesic drugs and also reduction of anaesthetic doses. In addition, clonidine increases cardiac baroreceptor reflex sensitivity to increase in systolic blood pressure, and thus stabilizes blood pressure. Clonidine is rapidly and almost completely absorbed after oral administration with a time to maximum plasma concentration of between 1.5 and $2 \mathrm{hr}$ and elimination half-life of 8 to $12 \mathrm{hr}$. But clonidine produces analgesia in a dose dependent manner, achieving complete pain relief for up to 5 hours without sensory or motor block at large doses (oral 7000 to $900 \mathrm{mcg}$ ) however large doss were associated with disadvantage including hypotension, bradycardia and transient sedation. It also reported that clonidine $150 \mathrm{mcg}$ intravenous (I/ V) produce a similar analgesic effect to morphine $5 \mathrm{mg}$ in patient after orthopedic surgery. Because of its dose, route, and surgical variation it is very much important to specify the dose for upper abdominal surgery.

The primary aim of this study aims to evaluate and compare the effects of clonidine premedication at different doses $(2 \& 4 \mathrm{mcg} / \mathrm{kg})$ on postoperative analgesia and haemodynamic status in upper abdominal surgery. To differentiate the premedication doses of oral clonidine for upper abdominal surgery.

\section{Methods:}

A hospital based Prospective Randomized double -blind study among adult consented patients aged 18 to 60 years with ASA (American society of Anesthesiologist) class -I and class-ii of both gender. After considering the inclusion and exclusion criteria the patients were randomized to receive Group: A ( $2 \mathrm{mcg} / \mathrm{kg}$ oral clonidine) and Group: B ( $4 \mathrm{mcg} /$ $\mathrm{kg}$ oral clonidine), one hour (60minutes) before surgery as an oral premedication. All groups were compared for preoperative analgesic, sedation and anxiety level along with changes of heart rate and mean arterial pressure prior to premedication and post-operative periods as follows VAS (visual analogue score) pain scores were collected from patients using a standard $10-\mathrm{cm}$ VAS pain ruler VAS measured every hour for first 6 hours, then 4 hours interval for the rest 18 hours and also preoperative VAS taken, pethedine (meperidine) requirement, vital signs (Bp, pulse, mean blood pressure, spo2, respirations), PONV (post-operative nausea and vomiting), sedation, recovery score for 1 st 6 hours and other side effects (nausea dizziness vomiting) will be measured for up to 24 hours after surgery. Intraoperative analgesic

drugs requirement and any postoperative complication were recorded. Detailed demographic data were collected from the informant and recorded in structured case report form. Clinical examination and relevant investigations were done meticulously. All collected questionnaire were checked very carefully to identify the error in the data. The data processing work consist of registration schedules, editing computerization, preparation of dummy table, analyzing and matching of data.

\section{Result:}

The present study evaluated the oral premedication with clonidine at 2 microgram per kg or 4 microgram per $\mathrm{kg}$ for post operative analgesia and haemodynamic stability of elective upper abdominal surgery patients. A total of 60 patients, 30 in each group, were evaluated. All groups are comparable with respect to the demographic and operational factors. No significant difference were between two groups with respect to age, gender, weight, time between oral premedication to anaesthetic induction, duration of anaesthesia and surgical procedure time.

In our study, we have used oral premedication with clonidine at a dose of $2 \mathrm{mcg}$ per $\mathrm{kg}$ and 4 mcg per $\mathrm{kg}$ and found doses to be effective for post operative analgesic and haemodynamic stability in upper abdominal surgery. 
The Effect of Oral Clonidine at Different Doses on Post-Operative Analgesic

Mondol MSH et al

Table-I

Comparison of pre and post operative pain VAS between Group-A (2mcg per $\mathrm{kg}$ ) and Group B (4 mcg per $\mathrm{kg}$ ).

\begin{tabular}{lccc}
\hline Pain (VAS)(CM) & Group -A & Group -B & P-value \\
\hline Just before (preoperative) premedication & 00 & 00 & - \\
Zero postoperative hour & 00 & 00 & \\
$1^{\text {st }}$ post operative hour. & $0.3 \pm 0.2$ & 00 & $>0.05$ \\
$2^{\text {nd }}$ post operativehour & $0.1 \pm 0.5$ & 00 & $>0.05$ \\
$3^{\text {rd }}$ post operative hour & $0.2 \pm 0.3$ & 00 & $>0.05$ \\
$4^{\text {th }}$ post operative hour & $0.9 \pm 1.6$ & $0.1 \pm 0.12$ & $<0.05$ \\
$5^{\text {th }}$ post operative hour & $2.8 \pm 2.2$ & $1.7 \pm 1.1$ & $>0.05$ \\
$6^{\text {th }}$ post operative hour & $4.3 \pm 2.4$ & $1.3 \pm 0.8$ & $>0.05$ \\
$10^{\text {th }}$ post operativehour & $2.3 \pm 0.4$ & $1.9 \pm 0.6$ & $>0.05$ \\
$14^{\text {th }}$ post operativehour & $1.9 \pm 0.7$ & $3.3 \pm 1.2$ & $>0.05$ \\
$18^{\text {th }}$ post operativehour & $2.0 \pm 0.8$ & $2.3 \pm 0.6$ & $>0.05$ \\
$22^{\text {th }}$ post operativehour & $1.9 \pm 1.4$ & $1.3 \pm 1.5$ & $>0.05$ \\
$24^{\text {th }}$ post operativehour & $1.6 \pm 1.2$ & $1.5 \pm 0.2$ & $>0.05$ \\
\hline
\end{tabular}

Repeated measure ANOVA statistics was done to analyzed the "P" refer to over all statistical difference between two groups $\mathrm{S}=$ significant intensity of post operative pain measured on VAS showed Group A expressed highest VAS at $6^{\text {th }}$ post operative hour Group -B showed highest VAS at $14^{\text {th }}$ post operative hour. So it is very clear to us that pethedine requirement of Group B ( $4 \mathrm{mcg} / \mathrm{kg}$ oral clonidine) is less than Group A ( $2 \mathrm{mcg} / \mathrm{kg}$ oral clonidine).

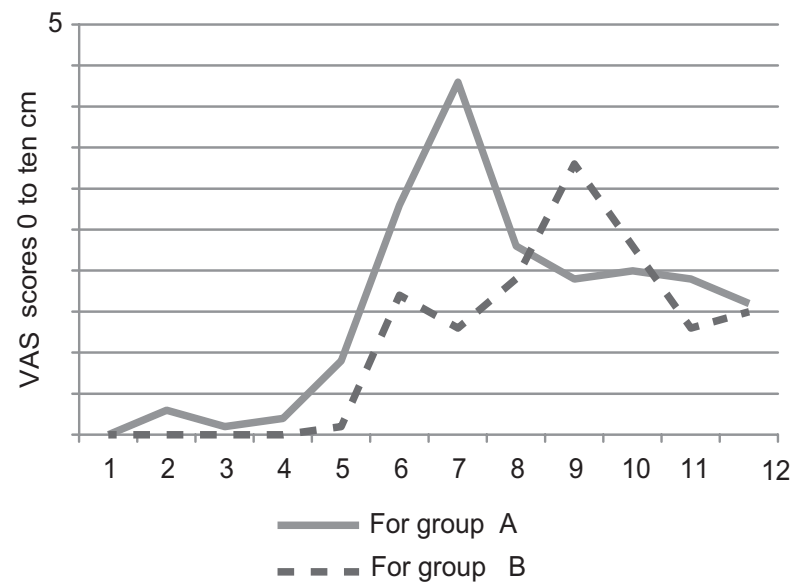

0 post operative hours, 1 to 6 is first 6 post operative hours gradually. $7^{\text {th }}$ for $10^{\text {th }}$ post operative hour, $8^{\text {th }}$ for $14^{\text {th }}$ post operative hour, $9^{\text {th }}$ for $18^{\text {th }}$ post operative hour, $10^{\text {th }} 22^{\text {th }}$ post operative hour, $11^{\text {th }}$ for $24^{\text {th }}$ post operative hour

\section{Discussion}

This prospective comparative study was carried out with an aim to evaluate the specific and effective analgesic dose of oral clonidine for premedication that plays an important role in post operative analgesia and stabilized the haemodynamic of patient who was operated by upper abdominal incision.

4 mcg per kg body weight of oral clonidine premedication in upper abdominal surgery is more effective than $2 \mathrm{mcg}$ per $\mathrm{kg}$ body weight, for post operative analgesia and haemodynamic stability, because of its large incision areas need more analgesic. On the other hand laparoscopic cholecystectomy $2 \mathrm{mcg}$ per $\mathrm{kg}$ is enough for it small incision.

Sung CS et al. ${ }^{18}$ found that the post operative analgesic requirement of clonidine premedicant $(150 \mathrm{mcg})$ was less and duration of first dose analgesic was prolonged (4.11 5.65) or $3 / 5$ hours in case of laparoscopic cholecystectomy. In our study group $\mathrm{A}$, which was premedicated by clonidine $2 \mathrm{mcg}$ per $\mathrm{kg}$ body weight was similar to the above mention study and it was suggested that the improvement of dose in certain level improve the analgesic duration on the post postoperative analgesic requirement period. 
Sing S Arora et al. ${ }^{10} 2011$ found that the premedicant by oral clonidine $150 \mathrm{mcg}$ was significantly decreased post operative analgesic requirement and improved perioperative haemodynamic stability and a reduction in intraoperative anaesthestic in case of laparoscopic cholecystectomy. They found most of the patient in clonidine group require no meperidine or only one dose during post operative 24 hours period, while more patient in the placebo group required 2 or more dose of meperidine. They suggested that administration of oral clonidine $150 \mathrm{mcg}$ as a simple and cost effective form of premedication in patient undergoing laparoscopic surgery. In our study the above mention dose was match with our group A $(2 \mathrm{mcg} / \mathrm{kg})$. However in case of large upper abdominal surgery dose of clonidine need to improved up to 4 or $5 \mathrm{mcg}$ per $\mathrm{kg}$. Brand JM 19 suggested that the preoperative use of oral clonidine $(3.5 \mathrm{mcg} / \mathrm{kg})$ followed by intravenous infusion of clonidine post operatively was found improved the haemodynamic profile associated with anaesthetic discontinuation, thus further proving its anesthetics sparing effect.

Mikawa K et al. 1996, 16 commented that oral clonidine premedication reduces post operative pain in children. They had recorded visual analogue score of 29 children to assess the post operative pain after minor surgery. They had given premedication $2 \mathrm{mcg} / \mathrm{kg}$ one group, $4 \mathrm{mcg} / \mathrm{kg}$ another group, and an placebo group. They had found VAS for placebo group was (6.6 \pm 1.7 ) (mean $\pm \mathrm{sd}, \mathrm{n}=11$ ) and VAS for group $(2 \mathrm{mcg} / \mathrm{kg})$ was $(5.7 \pm 1.5)$ (mean $\pm \mathrm{sd}, \mathrm{n}=10)$ and group ( $4 \mathrm{mcg} / \mathrm{kg}$ ) was $(4.4 \pm 1.6)$ (mean $\pm \mathrm{sd} n=8)$. According to their findings it was proved that different dose of clonidine differ in the post operative pain

management which is also granted our study that clonidine premedication is dose specific and surgery specific.

Regarding haemodynamic stability at post operative period fist 24 hours most of the patient of group B (premedicated by oral clonidine $4 \mathrm{mcg} / \mathrm{kg}$ ) was stable and in group $A$ (premedicated by oral clonidine $2 \mathrm{mcg} / \mathrm{kg}$ ) also stable except few hours when the analgesic effect of low dose clonidine declined. In the study of Hayash Y et al 199314 they found preoperative oral clonidine $(5 \mathrm{mcg} / \mathrm{kg})$ decreased the dose of droperidol necessary to maintain the haemodynamic stability at perioperative period in aortic surgery which support our results of group B.

Regarding mean blood pressure changes in post postoperative period there was significant difference found in both groups. Group B $(4 \mathrm{mcg} / \mathrm{kg})$ was found more effective in stabilizing the blood presser than group A $(2 \mathrm{mcg} / \mathrm{kg})$. This result is supported by previous studies like Kalra NK et al 2011. ${ }^{20}$ Found that clonidine $1.5 \mathrm{mcg} / \mathrm{kg}$ is far better than clonidine $1 \mathrm{mcg} / \mathrm{kg}$ in suppressing haemodynamic change during pneumoperitonium in lap cholecystectomy. Thalikder HA et al. 2015. ${ }^{3}$ Also found in lap cholecystectomy, clonidine $150 \mathrm{mcg}$ effectively attenuated the raise of heart rate and mean arterial blood pressure indicating inactivation of catecholamines. Borah et al 2017 4 found oral clonidine premedication $1 \mathrm{mcg} / \mathrm{kg}$ is effective in blunting the haemodynamic response to laryngoscopy in patient who undergoes surgery under general anaesthesia, intraoperative and post operative period. Mihosseni et al $2017^{6}$ found in their study clonidine $200 \mathrm{mg}$ induced less increase heart rate at 8 hours of operation and MABP peroperatively. Above study closely support our result that $4 \mathrm{mcg} / \mathrm{kg}$ oral clonidine premedication are more effective to stable the haemodynamic at whole post operative period 24 hours after upper abdominal surgery and low dose $2 \mathrm{mg} / \mathrm{kg}$ only for operative and early post operative period.

\section{Conclusion}

Upper abdominal surgery (like- hepatobiliary surgery, gastrectomy, esophagectomy, hepatectomy, and whipples operations that involve large surgical incisions) lead to severe post operative pain that lead to higher doses of opoids use in post operative period as a result incidence of unwanted side effect and respiratory complication increase hospital stay and morbidity. As a part of multimodal analgesic approach, $4 \mathrm{mcg} / \mathrm{kg}$ oral clonidine premedication is effective to perioperative pain control and keep stable the haemodynamic in upper abdominal surgery. 


\section{References:}

1. Ahmed NU, Hossain M, Akhtaruzzaman AKM, Mondol MK, Khatun UHS, Addition of clonidine or fentanyl with Bupivacaine for supraclavicular brachial plexus blocks in upper limb surgery. JBSA 2011; 24(1):3-7.

2. Islam A, Hossain M, Akhtaruzzaman AKM, Khatun UHS, study on role of oral clonidine in laparoscopic cholecystectomy surgery - A comperative study. JBSA2008; 21(1):12-20.

3. Talukder HA, Rahman MA, Begum R, Effectiveness of oral clonidine and oral gabapentin in attenuation of haemodynamic stress response to laparoscopic cholecystectomy -A placebo control trial. 2015, Dissertation, BCPS.

4. Borah B, Shukla I M, Joshi NK, Parasmani, A comperative study between dexmedittomidines, clonidine and magnesium sulfate in attenuating hemodynamic response to laryingoscopy and intubation -A randomized study. Indian Journal of ClinicalAnaesthesia. 2017; 04(1): 30-36.

5. Beaudoin FL, Lin C, Guan W, Merchant RC, Low-dose Ketamine Improves Pain Relief in Patients Receiving Intravenous Opioids for Acute Pain in the Emergency
Department: Results of a Randomized, Double-blind, Clinical Tria. The society of Academia emergency Medicine 2014; 10: 1111

6. Mirhosseinei H, Bidaki R. Effect of Oral clonidine on shoulder Tip Pain and Haemodynamic Response after laparoscopic cholecystectomy. Anaesthesia and pain medicine. 2017. 61669.

7. Park J, \& R Kolesar, Oral clonidine reduces postoperative PCA morphine requirements.CAN Journal of anaesthesia, 1996; 43: 900-6

8. Pain assessment European spine journal 2006.15(1):S17-S24

9. Nitta R, Goyan T, Nitshikawa T, Combination of oral clonidine and intravenous low dose ketamine reduces the consumption of postoperative patient controlled analgesia morphine after spine surgery. ActaAnaesthesiologicataiwanica 2013; 51:14-

10. Singh S, Arora K, Effect of oral clonidine premedication on perioperative haemodynamic response and post operativeanalgesisic requirement for patients undergoing laparoscopic cholecystectomy. Indian Journal of Anaesthesia. 2011 55(1): 26-30 